\title{
Hormonal correlations of premature ejaculation
}

\author{
Andrea Sansone $\cdot$ Francesco Romanelli • \\ Emmanuele A. Jannini · Andrea Lenzi
}

Received: 18 November 2014/ Accepted: 21 December 2014

(C) Springer Science+Business Media New York 2014

\begin{abstract}
Premature ejaculation is the most frequent male sexual dysfunction, significantly impairing quality of life of both the patient and the partner and affecting up to onethird of men of every age. In the last years, our knowledge about this topic has greatly increased, and studies on the causes and treatments related to ejaculatory disorders have shed a light on previously uncharted territory. Public interest on sexual dysfunctions has likewise increased in the general population: the time lapse between the first symptoms of sexual dysfunction and the seeking of medical advice has been significantly reduced, whereas demand for a treatment has markedly increased. A role of endocrine regulation has been established in all the aspects of male reproduction; however, the endocrine control of ejaculation is not fully understood. Sex steroid, pituitary, and thyroid hormones have all been advocated as potential candidates in the regulation of the ejaculatory process, but exact mechanisms are not clear yet and further studies are required in order to identify potential targets for treatment.
\end{abstract}

Keywords Premature ejaculation - Orgasm - Hormones · Delayed ejaculation

\footnotetext{
A. Sansone $(\square) \cdot$ F. Romanelli · A. Lenzi

Section of Medical Pathophysiology, Food Science and

Endocrinology, Department of Experimental Medicine,

"Sapienza" University of Rome, Viale Regina Elena, 324, 00161 Rome, Italy

e-mail: andrea.sansone@uniroma1.it;

andreasansone85@gmail.com

E. A. Jannini

Department of Systems Medicine, Tor Vergata University of Rome, Via Montpellier, 1, 00133 Rome, Italy
}

\section{Introduction}

Although consistent information about its prevalence is lacking [1], premature ejaculation (PE) is the most frequent male sexual disorder [2]: according to different criteria, its prevalence might widely vary, ranging from 8 to $30 \%$ [3] up to 22-38\% [4] in all age groups, yet very few men seek treatment. PE is "a culture-dependent symptom that is selfidentified, self-reported, and self-rated". For this reason, a conclusive definition is hard to reach: many authors and several scientific societies have provided different definitions of PE [5], classifying PE on time of onset, pathogenesis, and situational occurrence. Nonetheless, three common constructs underlie most definitions of PE: (1) brief ejaculatory latency; (2) loss of control; and (3) psychological distress in the patient and/or partner.

The Diagnostic and Statistical Manual of Mental Disorders, Fifth Edition (DSM-5) definition of PE includes the approximately 1-minute intravaginal ejaculatory latency time (IELT) criteria as well as the inclusion of distress. It also asks the clinician to specify the subtypes of lifelong and acquired, generalized, or situational dysfunction as well as its severity. Anteportal ejaculation is the term applied to men who ejaculate prior to vaginal penetration and is considered the most severe form of PE [6].

In 1917, PE was considered a symptom of neurosis, requiring psychoanalysis; in later years a more "psychobiological" view was hypothesized and PE was considered a psychosomatic disorder [7]. In the seventies, Masters and Johnson postulated that PE occurred as the result of a learned behavior; this definition was considered the most up to date until the end of the century, when Waldinger identified genetic and neurobiological determinants of PE $[8,9]$. A "Manichean" distinction between psychogenic and organic pathogenesis of PE is under close scrutiny, and 
represents one of the most frequent controversies in sexual medicine [10, 11]: neurotransmitters are involved as much as psychological issues [12], partially explaining the differences between lifelong and acquired forms of PE.

However, it is important to consider the fundamental role of the partner in determining the development of PE. In fact, $\mathrm{PE}$ is maybe the only partner-oriented male sexual symptom, since the ejaculatory precocity refers to partner sexual physiology and to the time course of the female sexual response [13]. Hence, the PE lives only inside of the couple.

In the field of male sexual dysfunctions, PE and erectile dysfunction (ED) are frequently coexistent in the same subject $[14,15]$ : based on their role on erectile function and sexual drive, hormones have been recently investigated in order to assess the exact endocrine mechanisms pertaining to ejaculation.

Androgens play a pivotal role in preserving sexual health [16, 17], but many other hormones are somehow involved in erectile function $[18,19]$ : even if more recent papers have provided a better insight on the endocrine control of the ejaculatory reflex $[20,21]$, existing guidelines on premature ejaculation provide little information on this matter [22-25]. The aim of this review is to provide a quick, easy-to-read reference which might be useful to the physician during clinical practice.

\section{Testosterone}

The role of testosterone in maintaining male sexual health has been elucidated in many papers, though its association with PE is still unclear [26]. It has been proven that testosterone affects the ejaculatory process [27], improving the control of ejaculation. In humans, testosterone acts on a peripheral level by regulating the expression and activity of nitric oxide (NO) synthase and type 5 phosphodiesterase (PDE5); It is known that high levels of intrapenile nitric oxide act as a local neurotransmitter to facilitate the relaxation of intracavernosal trabeculae, thereby maximizing blood flow and penile engorgement. In addition, the NO-PDE5 system also affects the ejaculation process by regulating the contractility of the male genital tract [28, 29]. As a result, a low testosterone level may reduce the volume of ejaculate in hypogonadal patients [30] leading to a delayed ejaculation. Clinical studies have confirmed those pathophysiological aspects of testosterone showing that hypogonadal men are usually prone to develop delayed ejaculation, whereas higher levels of testosterone are often correlated to PE.

In animal models, testosterone has proven to be able to exert its effects on different levels: at hypothalamic level, higher levels of testosterone are able to suppress serotonin, leading to a development of PE [31], whereas at spinal level testosterone regulates nuclei involved in the control of ejaculation. These findings, however, have yet to be confirmed in humans.

In addition, the literature evidence regarding the gonadotropins role related to PE is still severely lacking. A recent research found no significant correlation between luteinizing hormone ( $\mathrm{LH})$ and PE, although patients with PE had significantly higher levels of follicle stimulating hormone (FSH) [32]; these results, however, disagree with previous findings on the same topic [26].

\section{Estrogens}

Antagonism between testosterone and estradiol is often suggested as a possible cause of ED [33-35]. Estrogens are classically involved in female sexual excitation, but their receptors (ER- $\alpha$ and ER- $\beta$ ) have been discovered in the epididymis of rabbits and other animal species [36]. Some authors have hypothesized that estrogens are also involved in epididymal contractility in humans and are designated to achieve fertility [37]. Furthermore, estrogens are fundamental for activities involving the sympathetic activity of smooth muscle cells [38], including sexual stimulation.

\section{Oxytocin}

Oxytocin is an oligopeptide synthesized in the paraventricular and supraoptic hypothalamic nuclei and secreted by the posterior pituitary gland and it is mostly known for its role in stimulating lactation; however, its role in males has not been fully investigated. Research on this topic has shown that oxytocin is a potent inducer of penile erection in rodents [39]; based on these findings, more recent studies have shown that oxytocin levels in human plasma greatly increase during orgasm [40]. In rats, oxytocin showed a facilitatory effect on ejaculation by reducing the ejaculatory latency time and post-coital refractory time [41]; on the other hand, rodents with lower oxytocin levels had longer mount and refractory time, providing further demonstration of a role of this hormone on ejaculation [42]. However, administration of exogenous oxytocin has not shown the expected results: in a small group of healthy men, intranasal application of oxytocin did not have any significant effect on sexual behavior [43]. On the other hand, oxytocin receptors blockade via highly selective antagonists has shown promising effects in treating PE [44]. Oxytocin facilitates male and female reproductive behavior [45]: increased central and peripheral oxytocin levels perhaps might provide an answer to the role of the serotoninergic system in facilitating erection, ejaculation, and penile detumescence [46]. There are still a few missing pieces from this puzzle but we can assume that research on 
oxytocin and its relation to ejaculation disorders is far from being complete.

\section{Prolactin}

In female mammalians, prolactin (PRL) is involved in lactation; however, in males elevated PRL levels inhibit pulsatile secretion of gonadotropin-releasing hormone (GnRH), leading to a form of secondary hypogonadism. High PRL levels might impair sexual function in otherwise healthy men: this rarely happens in mild hyperprolactinemia $(>20 \mathrm{ng} / \mathrm{ml}$ ) but becomes a more common finding in severe hyperprolactinemia $(>35 \mathrm{ng} / \mathrm{ml})$. Elevated PRL is most commonly associated with delayed ejaculation, whereas lower PRL has been observed more consistently in patients suffering from PE; these findings have been confirmed even after adjusting for age, body mass index, medicaments, and smoking habit. Low PRL levels have also been observed in patients with high anxiety and guiltiness during masturbation, suggesting perturbations of the neurological pathway involving serotonin and its receptors. In a consecutive series of 2,531 outpatients consulting for sexual dysfunctions, PRL in the lowest quartile levels is associated with Metabolic Syndrome and ED, as well as with PE and anxiety symptoms [47]. However, in a recent study [32], no significant difference was found between PRL levels of subjects with PE and healthy men: it seems that there is still a lot to be discovered regarding the role of PRL in ejaculation disorders.

\section{Thyroid hormones}

The effect of thyroid hormones on human behavior has been thoroughly investigated. Receptors for thyroid hormones have been found in the male genital tract [48]: based on this assumption, a role of thyroid hormones in PE has been postulated [49]. Hyperthyroidism in animal models has been advocated as a possible cause, or even a risk factor, of premature ejaculation $[50,51]$ : even if the first studies in men did not lead to certain results [52], a role of thyroid hormones has been already confirmed in humans [53]. Treatment of hyperthyroidism has proven to be effective for PE: after normalizing thyroid function in hyperthyroid men, the prevalence of PE fell from 50 to $15 \%$ [49]. A role for hyperthyroidism-induced anxiety in causing PE was also investigated [54, 55]. However, at multivariate analysis, even after adjusting for anxiety, a low TSH was independently predictive of PE [54]. It was also shown the medical treatment of the opposite state, hypothyroidism, resulted in a twofold decrease in ejaculatory latency [47]. Hence, both hyper- and hypothyroidism have been advocated as causes of sexual health disorders [56]: diagnosing and treating thyroid disorders might have lead to a significant improvement in quality of life. However, the assessment should be made only after performing careful medical history and physical examination, in order to evaluate the most common features and symptoms of hypo- or hyperthyroidism.

\section{Adrenal hormones}

To date, literature is severely lacking regarding the role of adrenal hormones in PE. Among adrenal androgens, androstenedione, DHEA, and DHEAS are undoubtedly the most important ones; however, only DHEA and DHEAS have been investigated as a possible cause of sexual dysfunction. The routine evaluation of DHEA and DHEAS has not been recommended in assessment of erectile function; as for what concerns PE, there are scanty evidences regarding the hormonal involvement in its pathogenesis.

Cortisol is undoubtedly the most known adrenal hormone: its role on metabolism has been thoroughly investigated, although evidence on its role on sexual dysfunction is still inconclusive. Stress management is involved in the pathogenesis of ED [57, 58]: considering the involvement of cortisol in coping with stress, we suppose that it might be interesting to evaluate cortisol levels in patients with $\mathrm{PE}$, even if literature does not provide evidence in this regard.

\section{Leptin}

Leptin, a hormone identified in 1994 and traditionally associated with satiety and energy expenditure, has been extensively studied in the last decades in order to identify its roles on other physiological processes. Leptin is involved in the regulation of different elements of the hypothalamic-pituitary-gonadal axis [59, 60], and its production might also occur autonomously in human spermatozoa [61]: based on these assumptions, a role for leptin in premature ejaculation has been postulated and studied [62, 63]. Elevated serum leptin seems to be significantly associated with PE: however, these studies have been led on a small scale, and the authors themselves suggest that more studies are necessary in order to consider leptin a marker or a diagnostic tool for PE.

\section{Conclusions}

Premature ejaculation is the most common male sexual dysfunction, and yet its pathophysiology remains not 


\begin{tabular}{|c|c|c|}
\hline$\uparrow$ risk DE & Testosterone & $\uparrow$ risk $\mathrm{PE}$ \\
\hline Unknown & Estradiol & $\uparrow$ risk $\mathrm{PE}$ \\
\hline$\uparrow$ risk $\mathrm{PE}$ & Prolactin & $\uparrow$ risk DE \\
\hline$\uparrow$ risk DE & Oxytocin & $\uparrow$ risk PE \\
\hline$\uparrow$ risk DE & FT3, FT4 & $\uparrow$ risk $\mathrm{PE}$ \\
\hline Unknown & Adrenal androgens & Unknown \\
\hline Unknown & Cortisol & Unknown \\
\hline Unknown & Leptin & $\uparrow$ risk $P E$ \\
\hline
\end{tabular}

Fig. 1 Effects of different hormones on ejaculation. $P E$ premature ejaculation. $D E$ delayed ejaculation

completely understood [64], though chronic prostatitis [6567], lack of privacy [68], and psychorelational/psychosexual issues [69] are considered important causes of PE. PE significantly affects the sexual life of the couple [13, 70], and has recently been identified as a frequent cause of relationship breakups [71]. Among the known secondary causes of PE, hormonal alterations might play a pivotal role; however, hormones are also frequently involved in other sexual disorders, therefore complicating the diagnosis (Fig. 1). Hyperthyroidism has been considered a cause of $\mathrm{PE}$, and its treatment has been found effective in delaying ejaculation; low levels of PRL have been found in patients suffering from PE, although hypoprolactinemia might be a marker of perturbations in the serotonin pathway. There seems to be still little evidence in regards to the involvement of other hormones in the pathogenesis of PE. Hence, we suggest the evaluation of testosterone, estradiol, PRL, leptin, adrenal hormones, and thyroid functioning only when significant symptoms suggesting the suspect of underlying diseases are observed. It should be clear that PE is often associated with endocrine diseases, requiring adequate investigation and follow-up by a trained specialist: the endocrinologist should be a reference during differential diagnosis of PE.

Conflict of interest The authors declare no existing conflict of interest.

\section{References}

1. D. Rowland, C.G. McMahon, C. Abdo, J. Chen, E.A. Jannini, M.D. Waldinger, T.Y. Ahn, Disorders of orgasm and ejaculation in men. J. Sex. Med. 7, 1668-1686 (2010)
2. G. Corona, E.A. Jannini, F. Lotti, V. Boddi, G. De Vita, G. Forti, A. Lenzi, E. Mannucci, M. Maggi, Premature and delayed ejaculation: two ends of a single continuum influenced by hormonal milieu. Int. J. Androl. 34, 41-48 (2011)

3. E.A. Jannini, A. Lenzi, Epidemiology of premature ejaculation. Curr. Opin. Urol. 15, 399-403 (2005)

4. E.J. McCarty, W.W. Dinsmore, Premature ejaculation: treatment update. Int. J. STD AIDS 21, 77-81 (2010)

5. C.G. McMahon, E.A. Jannini, M. Waldinger, D. Rowland, Standard operating procedures in the disorders of orgasm and ejaculation. J. Sex. Med. 10, 204-229 (2013)

6. American Psychiatric Association, The Diagnostic and Statistical Manual of Mental Disorders, 5th edn. (American Psychiatric Association, Washington, 2013)

7. M.D. Waldinger, History of Premature Ejaculation. Premature Ejaculation (Springer, Milano, 2012), pp. 5-24

8. M.D. Waldinger, M. Rietschel, M.M. Nöthen, M.W. Hengeveld, B. Olivier, Familial occurrence of primary premature ejaculation. Psychiatr. Genet. 8, 37-40 (1998)

9. M.D. Waldinger, H.H. Berendsen, B.F. Blok, B. Olivier, G. Holstege, Premature ejaculation and serotonergic antidepressantsinduced delayed ejaculation: the involvement of the serotonergic system. Behav. Brain Res. 92, 111-118 (1998)

10. E.A. Jannini, A. Lenzi, Ejaculatory disorders: epidemiology and current approaches to definition, classification and subtyping. World J. Urol. 23, 68-75 (2005)

11. E.A. Jannini, M.P. McCabe, A. Salonia, F. Montorsi, B.D. Sachs, Organic vs. psychogenic? The Manichean diagnosis in sexual medicine. J. Sex. Med. 7, 1726-1733 (2009)

12. E.A. Jannini, C. Simonelli, A. Lenzi, Sexological approach to ejaculatory dysfunction1. Int. J. Androl. 25, 317-323 (2002)

13. E. Limoncin, M. Tomassetti, G.L. Gravina, G. Ciocca, E. Carosa, S. Di Sante, V. Gentile, V. Mirone, F. Montorsi, A. Lenzi, E.A. Jannini, Premature ejaculation results in female sexual distress: standardization and validation of a new diagnostic tool for sexual distress. J. Urol. 189, 1830-1835 (2013)

14. E.A. Jannini, A.M. Isidori, A. Aversa, A. Lenzi, S.E. Althof, Which is first? The controversial issue of precedence in the treatment of male sexual dysfunctions. J. Sex. Med. 10, 2359-2369 (2013)

15. E.A. Jannini, F. Lombardo, A. Lenzi, Correlation between ejaculatory and erectile dysfunction. Int. J. Androl. 28, 40-45 (2005)

16. S. Basaria, Male hypogonadism. Lancet 383, 1250-1263 (2014)

17. F. Romanelli, A. Sansone, A. Lenzi, Erectile dysfunction in aging male. Acta Biomed. 81(Suppl 1), 89-94 (2010)

18. A. Sansone, F. Romanelli, D. Gianfrilli, A. Lenzi, Endocrine evaluation of erectile dysfunction. Endocrine 46, 423-430 (2014)

19. M. Maggi, J. Buvat, G. Corona, A. Guay, L.O. Torres, Hormonal causes of male sexual dysfunctions and their management (hyperprolactinemia, thyroid disorders, GH disorders, and DHEA). J. Sex. Med. 10, 661-677 (2013)

20. G. Corona, E.A. Jannini, L. Vignozzi, G. Rastrelli, M. Maggi, The hormonal control of ejaculation. Nat. Rev. Urol. 9, 508-519 (2012)

21. M.I. Öztürk, O. Koca, M. Tüken, M.O. Keles, A. Ilktaç, M.I. Karaman, Hormonal evaluation in premature ejaculation. Urol. Int. 88, 454-458 (2012)

22. S.E. Althof, C.H.N. Abdo, J. Dean, G. Hackett, M. McCabe, C.G. McMahon, R.C. Rosen, R. Sadovsky, M. Waldinger, E. Becher, G.A. Broderick, J. Buvat, I. Goldstein, A.I. El-Meliegy, F. Giuliano, W.J.G. Hellstrom, L. Incrocci, E.A. Jannini, K. Park, S. Parish, H. Porst, D. Rowland, R. Segraves, I. Sharlip, C. Simonelli, H.M. Tan, International Society for Sexual Medicine: international Society for Sexual Medicine's guidelines for the diagnosis and treatment of premature ejaculation. J. Sex. Med. 7, 2947-2969 (2010) 
23. K. Hatzimouratidis, E. Amar, I. Eardley, F. Giuliano, Guidelines on male sexual dysfunction: erectile dysfunction and premature ejaculation. Eur. Urol. 57, 804-814 (2010)

24. E.C. Serefoglu, T.R. Saitz, New insights on premature ejaculation: a review of definition, classification, prevalence and treatment. Asian J. Androl. 14, 822-829 (2012)

25. S.E. Althof, C.G. McMahon, M.D. Waldinger, E.C. Serefoglu, A.W. Shindel, P.G. Adaikan, E. Becher, J. Dean, F. Giuliano, W.J.G. Hellstrom, A. Giraldi, S. Glina, L. Incrocci, E.A. Jannini, M. McCabe, S. Parish, D. Rowland, R.T. Segraves, I. Sharlip, L.O. Torres, An update of the International Society of Sexual Medicine's guidelines for the diagnosis and treatment of premature ejaculation (PE). J. Sex. Med. 11, 1392-1422 (2014)

26. P.G. Cohen, The association of premature ejaculation and hypogonadotropic hypogonadism. J. Sex. Marital Ther. 23, 208-211 (1997)

27. G. Corona, E.A. Jannini, E. Mannucci, A.D. Fisher, F. Lotti, L. Petrone, G. Balercia, E. Bandini, V. Chiarini, G. Forti, M. Maggi, Different testosterone levels are associated with ejaculatory dysfunction. J. Sex. Med. 5, 1991-1998 (2008)

28. G. Corona, M. Maggi, The role of testosterone in erectile dysfunction. Nat Rev Urol. 7, 46-56 (2010)

29. A. Morelli, S. Filippi, R. Mancina, M. Luconi, L. Vignozzi, M. Marini, C. Orlando, G.B. Vannelli, A. Aversa, A. Natali, G. Forti, M. Giorgi, E.A. Jannini, F. Ledda, M. Maggi, Androgens regulate phosphodiesterase type 5 expression and functional activity in corpora cavernosa. Endocrinology 145, 2253-2263 (2004)

30. G. Corona, V. Boddi, M. Gacci, A. Sforza, G. Forti, E. Mannucci, M. Maggi, Perceived ejaculate volume reduction in patients with erectile dysfunction: psychobiologic correlates. J. Androl. 32, 333-339 (2011)

31. M.D. Waldinger, The neurobiological approach to premature ejaculation. J. Urol. 168, 2359-2367 (2002)

32. M.G. Mohseni, S.R. Hosseini, F. Alizadeh, N. Rangzan, Serum testosterone and gonadotropins levels in patients with premature ejaculation: a comparison with normal men. Adv. Biomed. Res. 3, 6 (2014)

33. B. Srilatha, P.G. Adaikan, Endocrine milieu and erectile dysfunction: is oestradiol-testosterone imbalance, a risk factor in the elderly? Asian J. Androl. 13, 569-573 (2011)

34. P.G. Adaikan, B. Srilatha, Oestrogen-mediated hormonal imbalance precipitates erectile dysfunction. Int. J. Impot. Res. 15, 38-43 (2003)

35. B. Srilatha, P.G. Adaikan, Y.S. Chong, Relevance of oestradioltestosterone balance in erectile dysfunction patients' prognosis. Singapore Med. J. 48, 114-118 (2007)

36. L. O'Donnell, K.M. Robertson, M.E. Jones, E.R. Simpson, Estrogen and spermatogenesis. Endocr. Rev. 22, 289-318 (2001)

37. R.A. Hess, Estrogen in the adult male reproductive tract: a review. Reprod. Biol. Endocrinol. 1, 52 (2003)

38. I.G. Motofei, The etiology of premature ejaculation starting from a bihormonal model of normal sexual stimulation. Int. J. Impot. Res. 13, 49-50 (2001)

39. A. Argiolas, M.R. Melis, G.L. Gessa, Oxytocin: an extremely potent inducer of penile erection and yawning in male rats. Eur. J. Pharmacol. 130, 265-272 (1986)

40. T.H.C. Krüger, P. Haake, D. Chereath, W. Knapp, O.E. Janssen, M.S. Exton, M. Schedlowski, U. Hartmann, Specificity of the neuroendocrine response to orgasm during sexual arousal in men. J. Endocrinol. 177, 57-64 (2003)

41. R. Arletti, C. Bazzani, M. Castelli, A. Bertolini, Oxytocin improves male copulatory performance in rats. Horm. Behav. 19, 14-20 (1985)

42. A.M. Hughes, B.J. Everitt, S.L. Lightman, K. Todd, Oxytocin in the central nervous system and sexual behaviour in male rats. Brain Res. 414, 133-137 (1987)
43. A. Burri, M. Heinrichs, M. Schedlowski, T.H.C. Kruger, The acute effects of intranasal oxytocin administration on endocrine and sexual function in males. Psychoneuroendocrinology. 33, 591-600 (2008)

44. P. Clément, J. Bernabé, S. Compagnie, L. Alexandre, S. McCallum, F. Giuliano, Inhibition of ejaculation by the nonpeptide oxytocin receptor antagonist GSK557296: a multi-level site of action. Br. J. Pharmacol. 169, 1477-1485 (2013)

45. J.G. Veening, T.R. de Jong, M.D. Waldinger, S.M. Korte, B. Olivier, The role of oxytocin in male and female reproductive behavior. Eur. J. Pharmacol. (2014). doi:10.1016/j.ejphar.2014. 07.045

46. M.D. Waldinger, Ejaculatio praecox, erectio praecox, and detumescentia praecox as symptoms of a hypertonic state in lifelong premature ejaculation: a new hypothesis. Pharmacol. Biochem. Behav. 121, 189-194 (2014)

47. G. Corona, E. Mannucci, E.A. Jannini, F. Lotti, V. Ricca, M. Monami, V. Boddi, E. Bandini, G. Balercia, G. Forti, M. Maggi, Hypoprolactinemia: a new clinical syndrome in patients with sexual dysfunction. J. Sex. Med. 6, 1457-1466 (2009)

48. E. Carosa, S. Di Sante, S. Rossi, A. Castri, F. D'Adamo, G.L. Gravina, P. Ronchi, Z. Kostrouch, S. Dolci, A. Lenzi, E.A. Jannini, Ontogenetic profile of the expression of thyroid hormone receptors in rat and human corpora cavernosa of the penis. J. Sex. Med. 7, 1381-1390 (2010)

49. C. Carani, A.M. Isidori, A. Granata, E. Carosa, M. Maggi, A. Lenzi, E.A. Jannini, Multicenter study on the prevalence of sexual symptoms in male hypo- and hyperthyroid patients. J. Clin. Endocrinol. Metab. 90, 6472-6479 (2005)

50. A. Cihan, N. Murat, O. Demir, G. Aslan, T. Demir, S. Gidener, A.A. Esen, An experimental approach to the interrelationship between hyperthyroidism and ejaculation latency time in male rats. J. Urol. 181, 907-912 (2009)

51. A. Cahangirov, A. Cihan, N. Murat, O. Demir, G. Aslan, S. Gidener, A.A. Esen, Investigation of the neural target level of hyperthyroidism in premature ejaculation in a rat model of pharmacologically induced ejaculation. J. Sex. Med. 8, 90-96 (2011)

52. M.D. Waldinger, A.H. Zwinderman, B. Olivier, D.H. Schweitzer, Thyroid-stimulating hormone assessments in a Dutch cohort of 620 men with lifelong premature ejaculation without erectile dysfunction. J. Sex. Med. 2, 865-870 (2005)

53. G. Corona, V. Ricca, E. Bandini, G. Rastrelli, H. Casale, E.A. Jannini, A. Sforza, G. Forti, E. Mannucci, M. Maggi, SIEDY scale 3, a new instrument to detect psychological component in subjects with erectile dysfunction. J. Sex. Med. 9, 2017-2026 (2012)

54. G. Corona, L. Petrone, E. Mannucci, E.A. Jannini, R. Mansani, A. Magini, R. Giommi, G. Forti, M. Maggi, Psycho-biological correlates of rapid ejaculation in patients attending an andrologic unit for sexual dysfunctions. Eur. Urol. 46, 615-622 (2004)

55. A. Cihan, O. Demir, T. Demir, G. Aslan, A. Comlekci, A. Esen, The relationship between premature ejaculation and hyperthyroidism. J. Urol. 181, 1273-1280 (2009)

56. G. Corona, F.C.W. Wu, G. Forti, D.M. Lee, D.B. O'Connor, T.W. O'Neill, N. Pendleton, G. Bartfai, S. Boonen, F.F. Casanueva, J.D. Finn, A. Giwercman, T.S. Han, I.T. Huhtaniemi, K. Kula, M.E.J. Lean, M. Punab, D. Vanderschueren, E.A. Jannini, E. Mannucci, M. Maggi, EMAS Study Group, Thyroid hormones and male sexual function. Int. J. Androl. 35, 668-679 (2012)

57. I. Kalaitzidou, M.S. Venetikou, K. Konstadinidis, A.K. Artemiadis, G. Chrousos, C. Darviri, Stress management and erectile dysfunction: a pilot comparative study. Andrologia 46, 698-702 (2013)

58. Y. Kobori, E. Koh, K. Sugimoto, K. Izumi, K. Narimoto, Y. Maeda, H. Konaka, A. Mizokami, T. Matsushita, T. Iwamoto, M. Namiki, The relationship of serum and salivary cortisol levels to 
male sexual dysfunction as measured by the International Index of Erectile Function. Int. J. Impot. Res. 21, 207-212 (2009)

59. M.J. Vázquez, A. Romero-Ruiz, M. Tena-Sempere, Roles of leptin in reproduction, pregnancy and polycystic ovary syndrome: consensus knowledge and recent developments. Metab. Clin. Exp. (2014)

60. M. Caprio, E. Fabbrini, A.M. Isidori, A. Aversa, A. Fabbri, Leptin in reproduction. Trends Endocrinol. Metab. 12, 65-72 (2001)

61. S. Aquila, M. Gentile, E. Middea, S. Catalano, C. Morelli, V. Pezzi, S. Andò, Leptin secretion by human ejaculated spermatozoa. J. Clin. Endocrinol. Metab. 90, 4753-4761 (2005)

62. M.R. Nikoobakht, P. Tajik, A.A. Karami, K. Moradi, A. Mortazavi, F. Kosari, premature ejaculation and serum leptin level: a diagnostic case-control study. J. Sex. Med. 5, 2942-2946 (2008)

63. B. Wang, C. Yang, K. Tang, Serum leptin and 5-hydroxytryptamine measurements for the diagnosis and treatment of premature ejaculation. Urology 82, 1336-1340 (2013)

64. A. Aversa, A. Lenzi, Sexual dysfunction: a practical approach to men with premature ejaculation. Nat. Rev. Urol. 11, 496-498 (2014)

65. E. Screponi, E. Carosa, S.M. Di Stasi, M. Pepe, G. Carruba, E.A. Jannini, Prevalence of chronic prostatitis in men with premature ejaculation. Urology 58, 198-202 (2001)
66. E.A. Jannini, C. Simonelli, A. Lenzi, Disorders of ejaculation. J. Endocrinol. Invest. 25, 1006-1019 (2014)

67. M.Q. Mo, L.L. Long, W.L. Xie, S. Chen, W.H. Zhang, C.Q. Luo, L.W. Deng, Sexual dysfunctions and psychological disorders associated with type IIIa chronic prostatitis: a clinical survey in China. Int. Urol. Nephrol. 46, 2255-2261 (2014)

68. V. Boddi, A.D. Fisher, E. Maseroli, G. Rastrelli, G. Corona, E.A. Jannini, V. Ricca, E. Mannucci, M. Maggi, Lack of sexual privacy affects psychological and marital domains of male sexual dysfunction. J. Sex. Med. 11, 431-438 (2013)

69. E.A. Jannini, M. Maggi, A. Lenzi, Evaluation of premature ejaculation. J. Sex. Med. 8(Suppl 4), 328-334 (2011)

70. R. Phillips, Sexual dysfunction: premature ejaculation and female sexual satisfaction. Nat. Rev. Urol. 11, 304 (2014)

71. A. Burri, F. Giuliano, C. McMahon, H. Porst, Female partner's perception of premature ejaculation and its impact on relationship breakups, relationship quality, and sexual satisfaction. J. Sex. Med. 11, 2243-2255 (2014) 